\title{
العلاقة بين الشكل والأرضية في الفن الحديث والاستفادة منها في فن التصوير
}

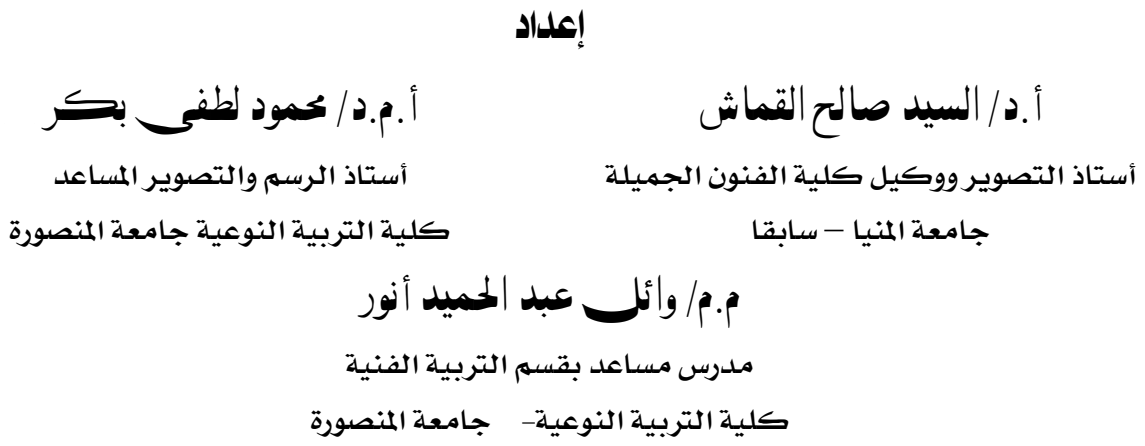




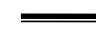

\title{
العلاقة بين الشكل والأرضية في الفن الحديث
}

والاستفادة منها في فن التصوير

\author{
إعداد

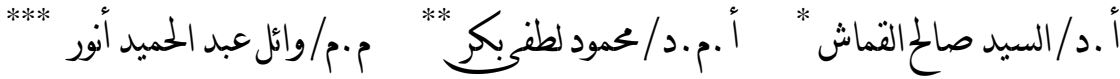

المضص :

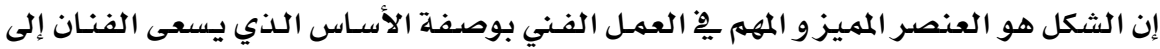

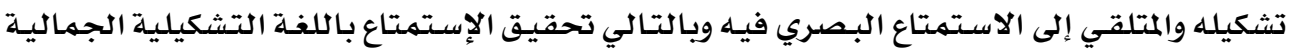

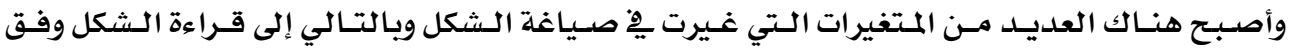

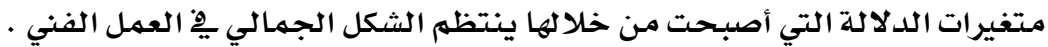

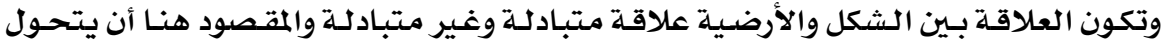

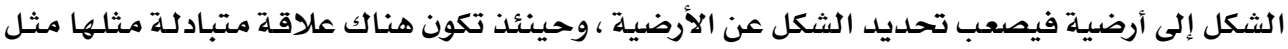

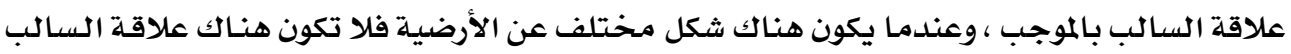

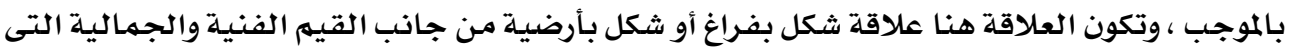

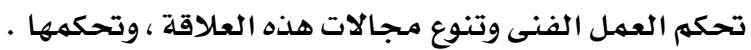

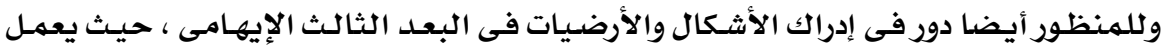

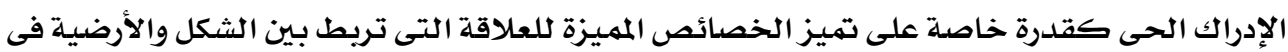
الفراغ

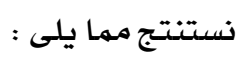

ا ـ الأرضية أكبر من الشكل وهى عادة مـاتكون أكثر بساطة ، ولكن ذلك لكات ينطبق على الدوام

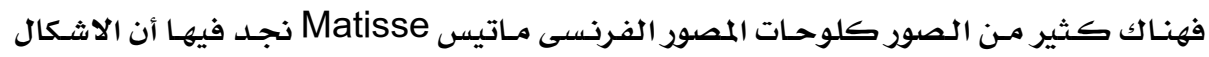

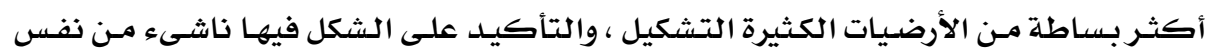

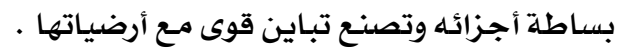

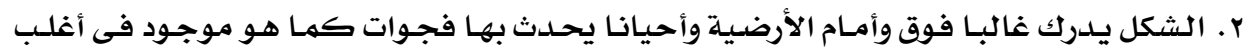

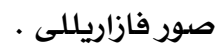
r. الأرضية يمكن إدراكها على أنها مسطح أو فضاء .

أستاذ التصوير ووكيل كلية الفنون الجميلة جامعة المنيا - سابقا

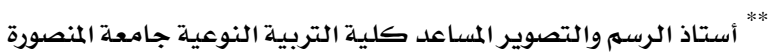
مدرس مساعد بقسم التربية الفنية كلية التربية النوعية- جامعة المنصورة 


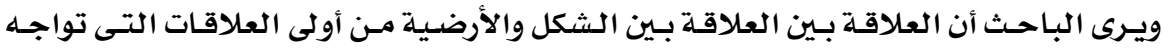

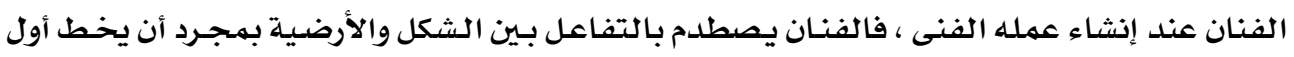

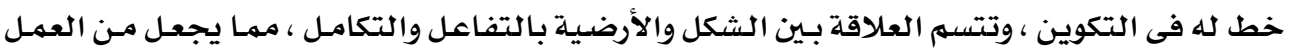

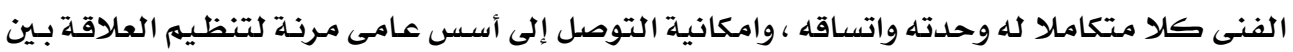

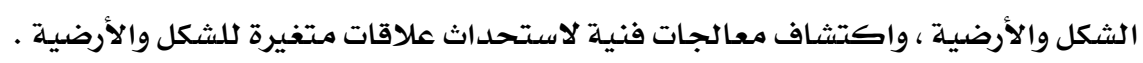

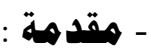

بعد تبلور الحداثة يْ أشكالها الجديدة منذ نهاية القرن التاسع عشر مـرورا بما بعد الحداثة،

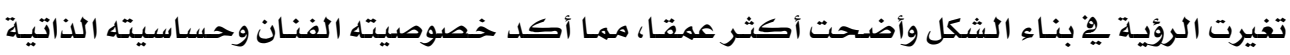

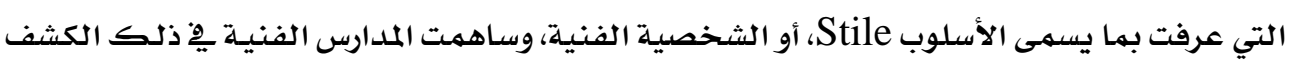

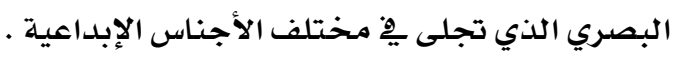

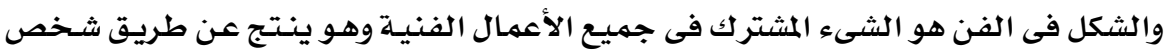

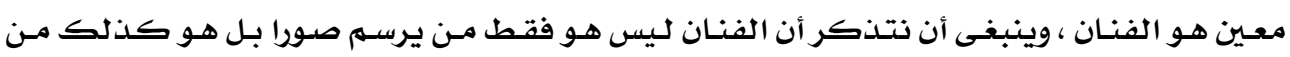

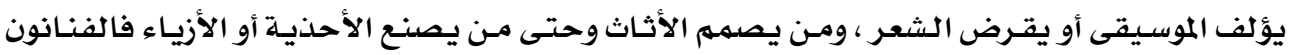

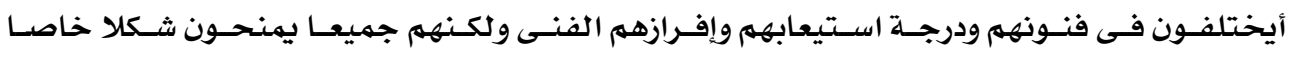

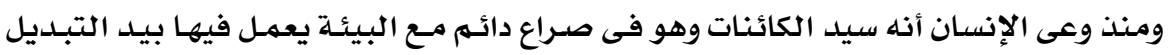

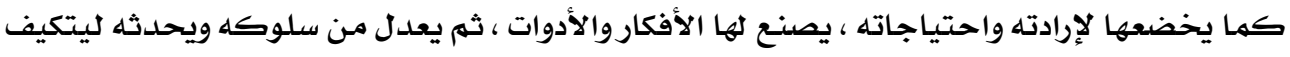

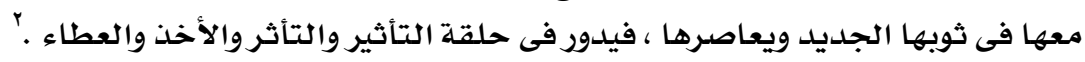

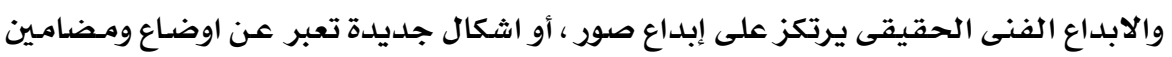

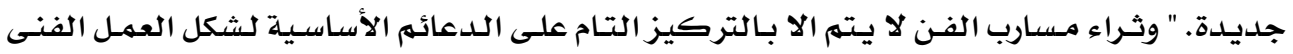

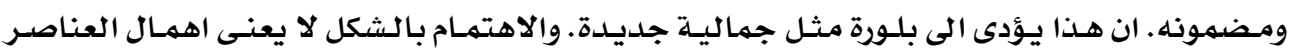
الجمالية الأخرى.

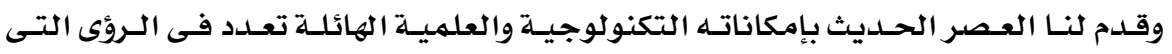

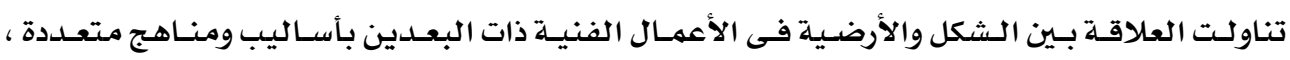

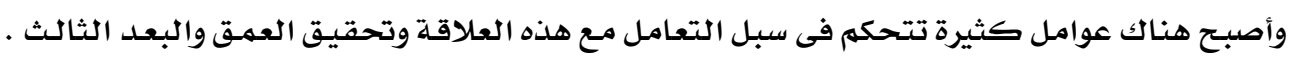

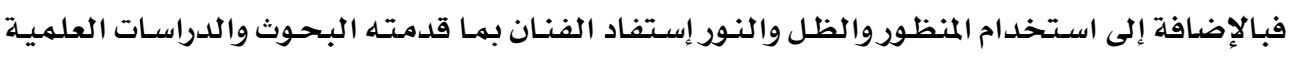

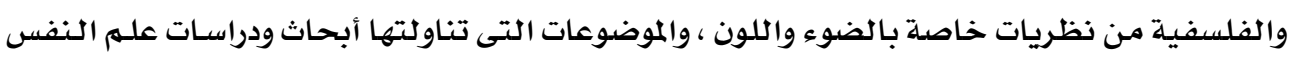

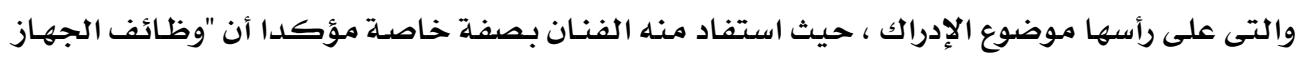

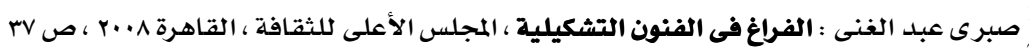

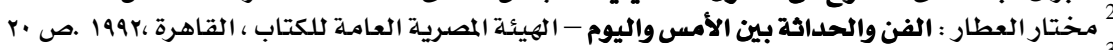

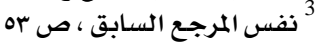




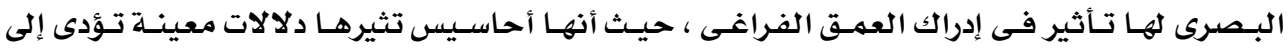

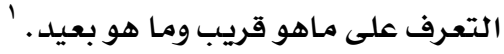

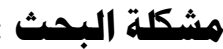

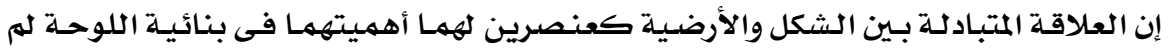

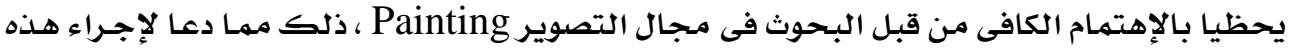

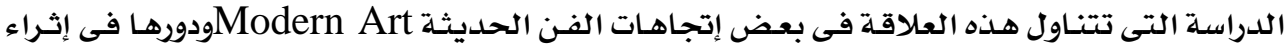

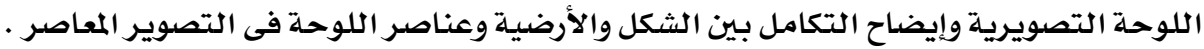
ويأتى دور الباحث فى تحديد مشكلة البحث فى الإجابة على التساؤل التالى :

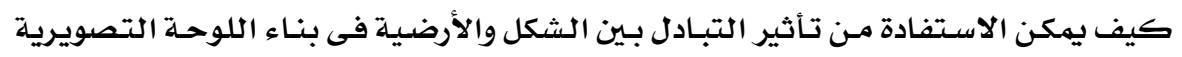

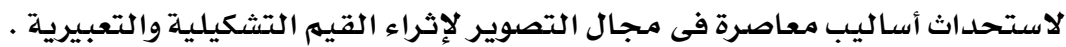

• تستند أهميـة البحـث إلى دراسـة مفهوم الشكل كعنصـر أسـاسى فى بنـاء الأعمال التصويرية ،

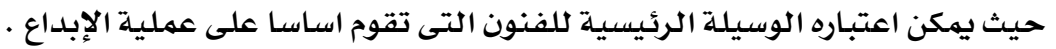

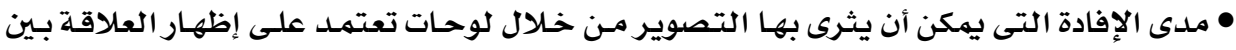

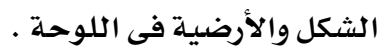

• طرح رؤى جديدة لإثراء الخيال التشكيلى وتعدد الرؤى لتأكيد أبجديات إبداعية جديدة .

• التعرف على إتجاهات وأساليب توظيف الشكل فى الأعمال الفنية ذات البعدين فى مختارات من

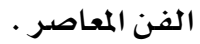

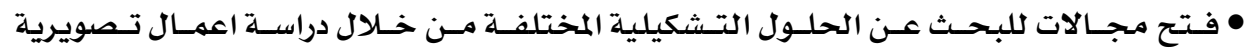
استخدمت علاقة الشكل بالأرضية لإثراء بنائية اللوحسة .

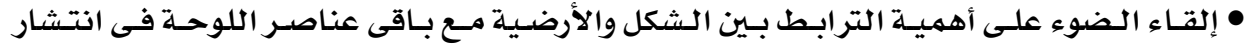

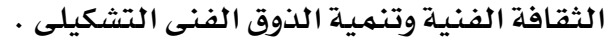

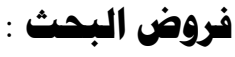
• توجد علاقة بين توظيف الشكل والأرضية والبناء التكوينى فى العمل الفنى .

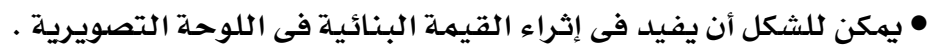
محممد ياسين أبو العنين : الدلالات الإدراكية للفراغ فى الأعمـال الفنيـة ذات البعدين فى مختـارات مـن الفن المعاصر

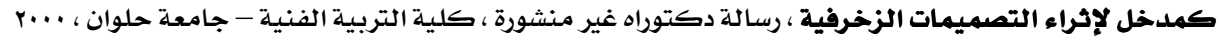




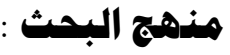

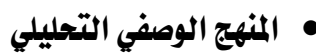

يقوم على تحليل مـا تضمنته مختارات مـن الاتجاهـات الفنيـة الحديثة للعلاقة بين الشكل

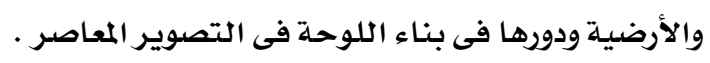

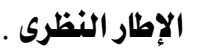

دراسة القيم التشكيلية للشكل وأنواع العلاقة بين الشكل والأرضية (تكامل - تبادل - تعادل). • • الإطار التطبيقى .

تجربة ذاتية يقوم بها الباحث للتأكيد على صدق وسلامة الفروض وتحقيق أهداف البحث.

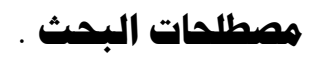

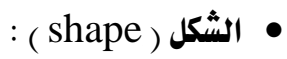

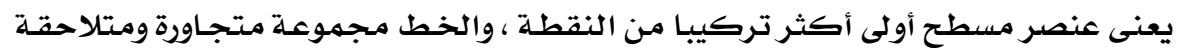

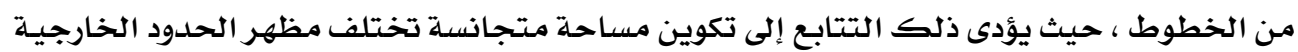

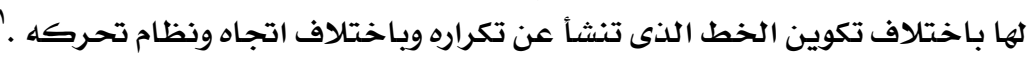

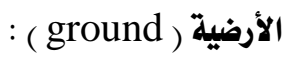

هى المساحة أو المنطقة التى ترتد خلف الأشكال أو تحيط بها أو تحيط بها أو توحى بلى بالفراغ

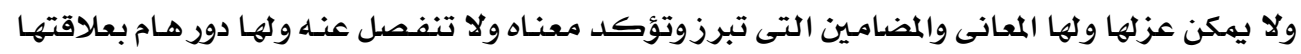

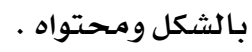

\section{الدراسات المرتبطة :}

• فى عام r199 م قدم الباحث إبراهيم عبد المغنى دراسة بعنوان:

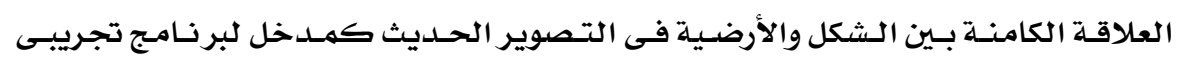

كتدريس التصوير

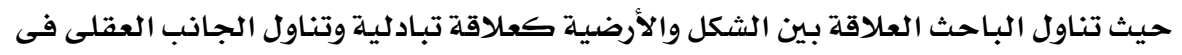

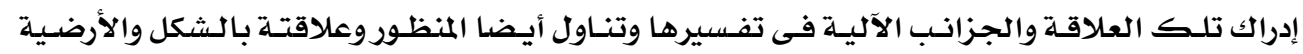

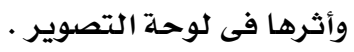

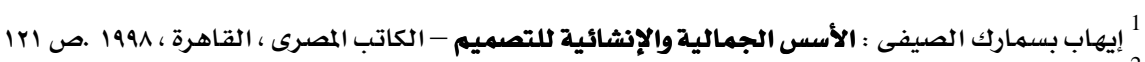

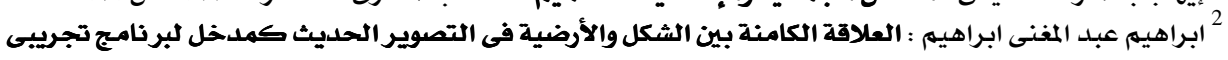

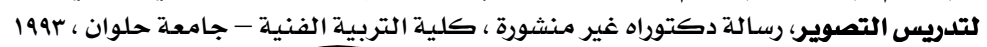


الشكل والفـراغ فى الشرافات المعماريـة الإسـلامية ، وأثرهـا فى إثراء التصميمـات الزخرفيـة

متعددة الأسطح · 'مشكل

حيث تناول فيها العلاقة بين الشكل والفراغ للشرافات المعماريـة الإسـالامية فى ضوء العلاقـة

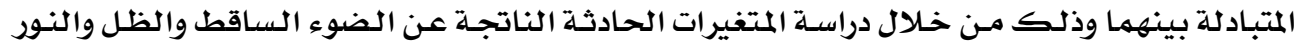

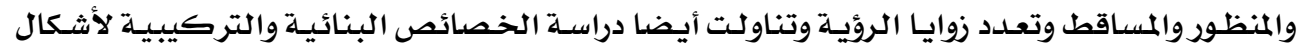

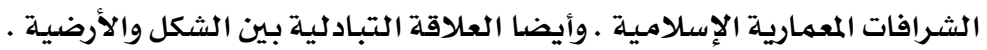

وقد تشابهت مـع موضوع البحث الحالى فى تناول العلاقة المتبادلة بين الشكل والفراغ وتأثيره

$$
\text { على ادرالك الرؤية . وقل تهابت. }
$$

\section{• فى عام 9 • . P م قدم الباحث مجدى أبو المعاطى البسيونى دراسـة بعنوان:}

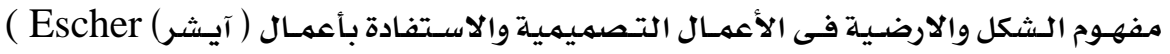

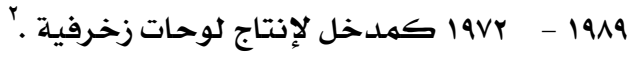

استهدفت الدراسـة تعريفان لمفهوم الشكل والارضية والعلاقة بينهما فى الطبيعة وفى الفنـون

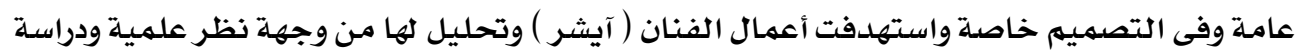

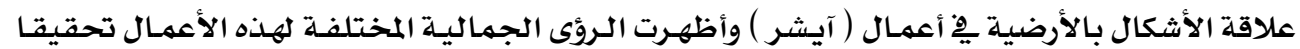

للتوازن والتماسك والقوة يِّ بناء الشكل .

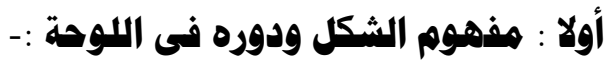

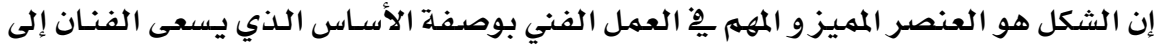

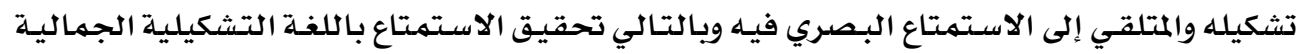

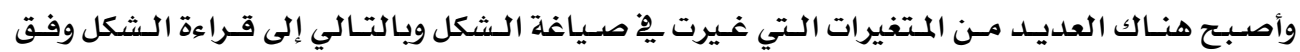

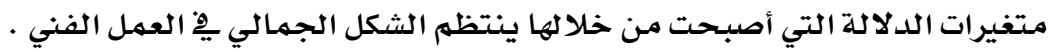

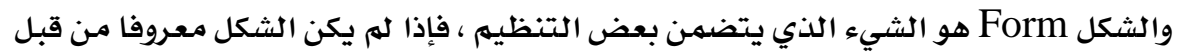

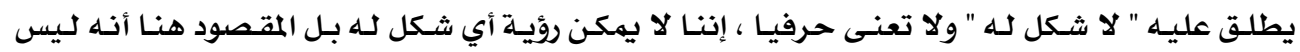

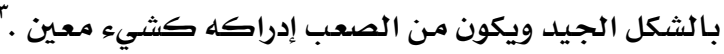

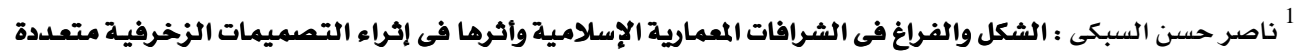

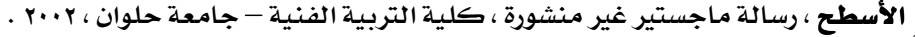

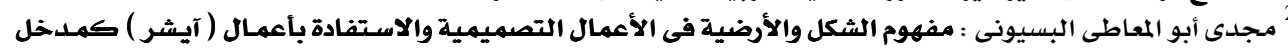

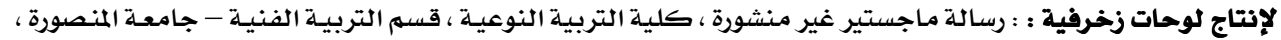

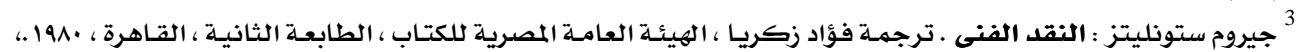


والشكل عبـارة عن كل مـا يحيط بالإنسان مـن ظواهر ووموجـودات محسوسة بحيث يشكل

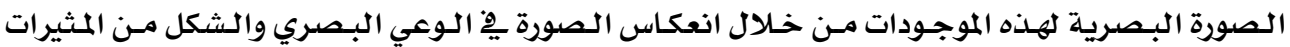

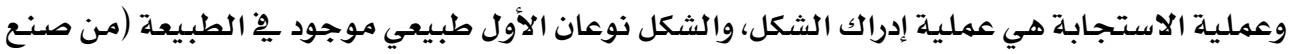

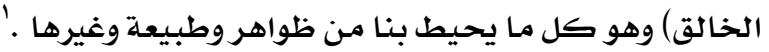
والثاني هو من صنـع الفنان فى الأعمال الفنية المختلفة .

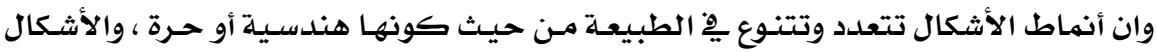

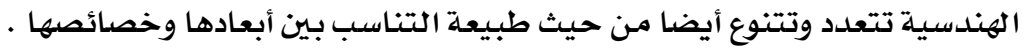

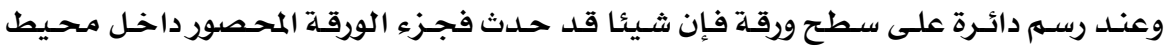

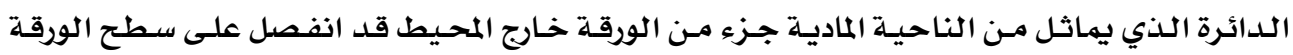

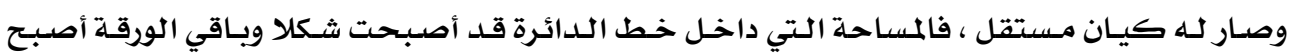
أرضيلة لها .

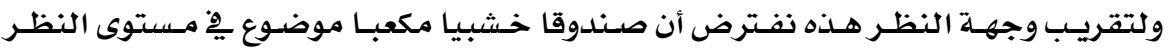

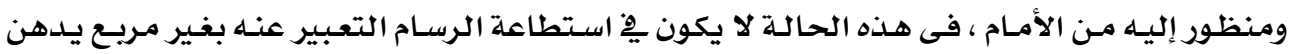

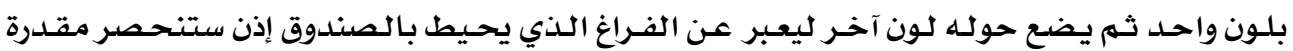

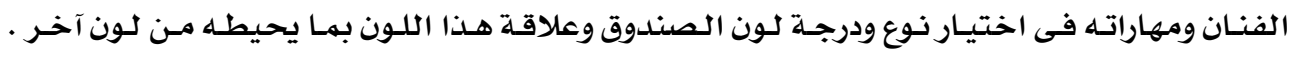

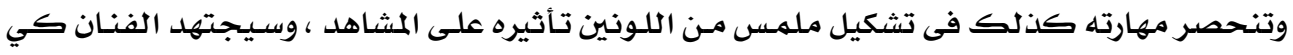

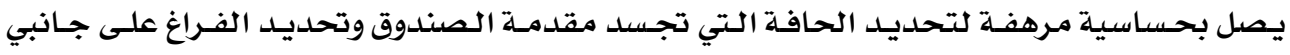

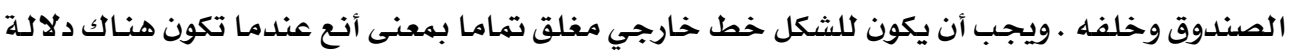
كافية على الإغلاق بحيث يمكن للعين أن تكمل الشكل.

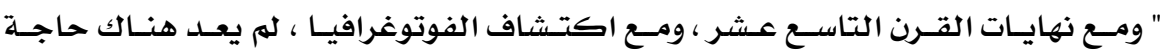

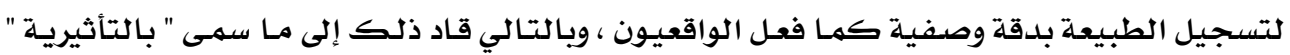

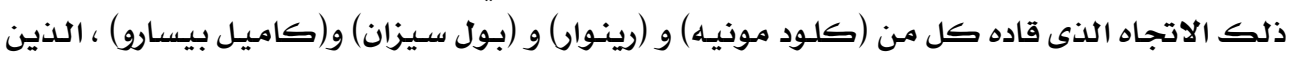

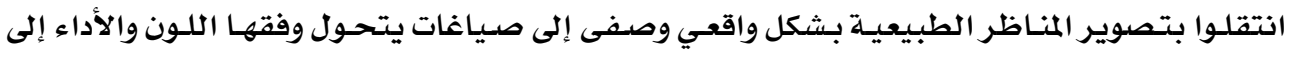

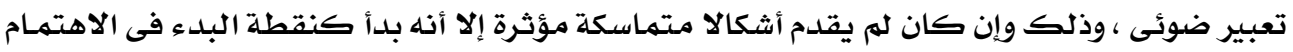

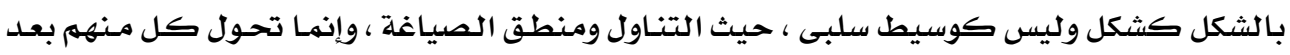

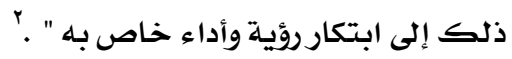

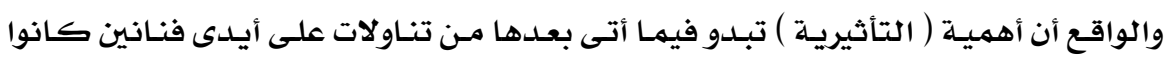

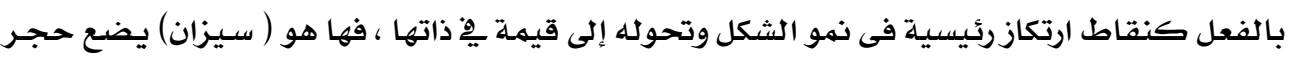

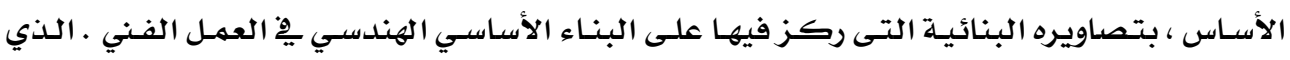

${ }^{1}$ http://www.basrahcity.net/pather/report/ammh/31.html

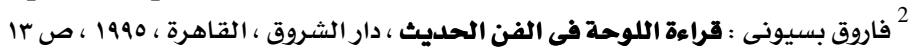


يعكس التعبير عن طريق قوة اللمستة وعلاقات الأشـكال وليس الموضـوع الوصفي أو الخيالي المطروح .

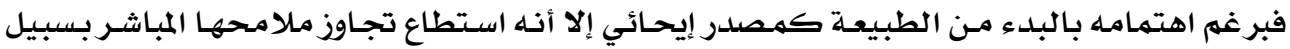

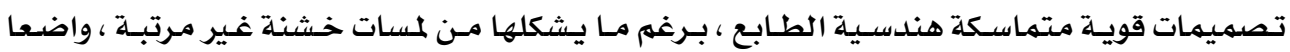

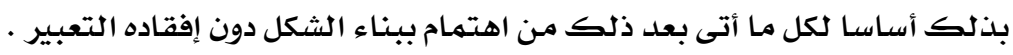

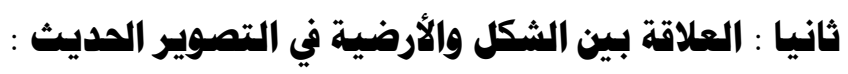

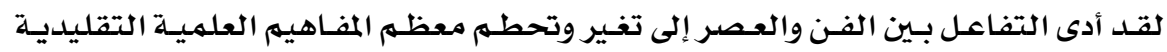

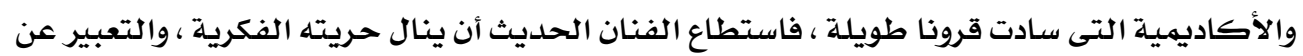

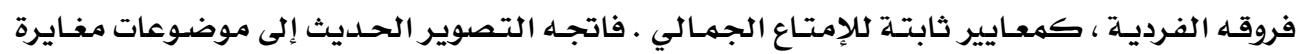

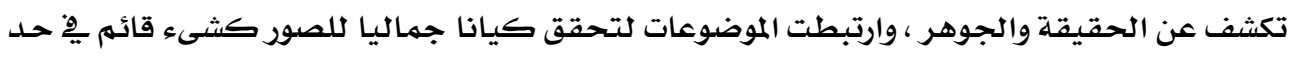

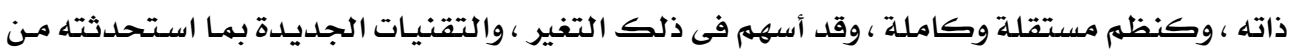

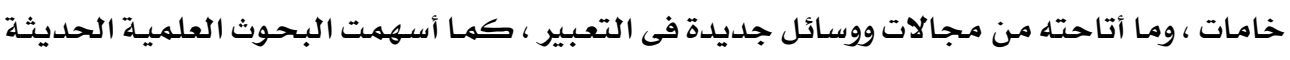

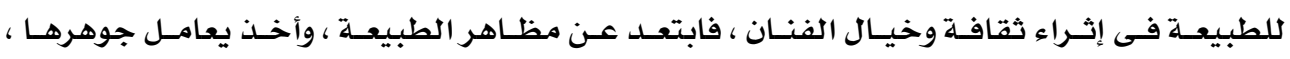

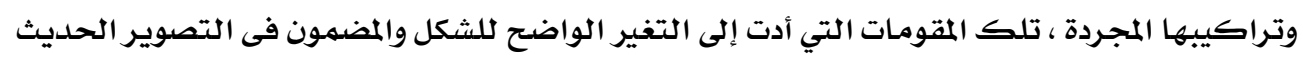

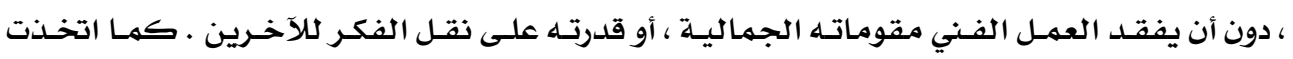

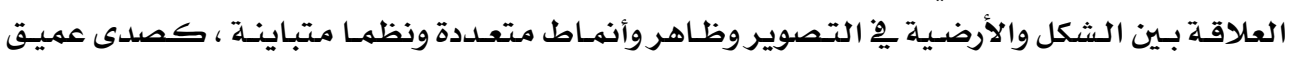

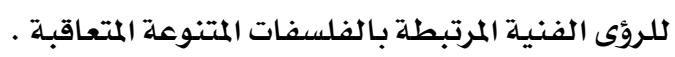

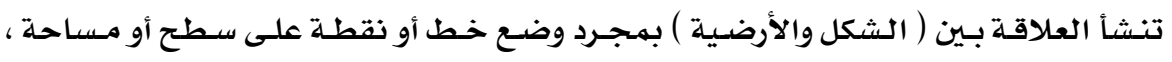

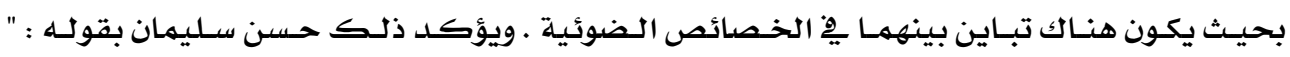

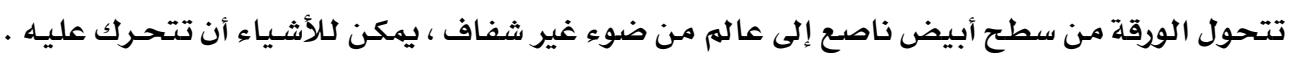

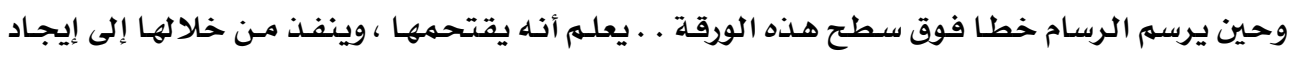

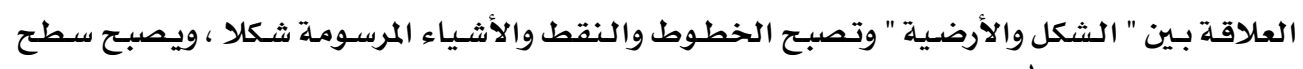

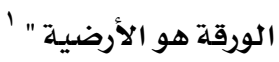

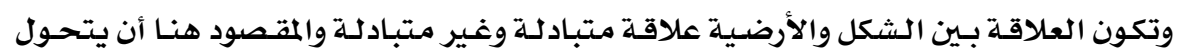

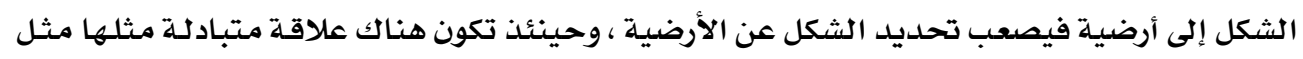

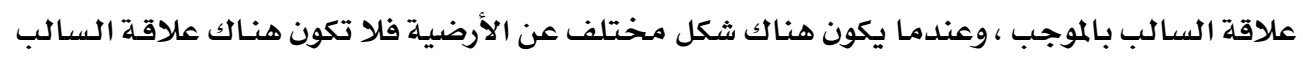

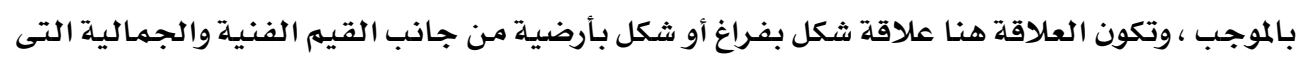

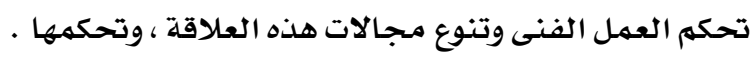

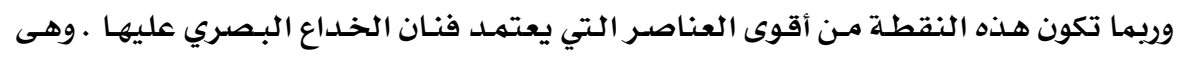

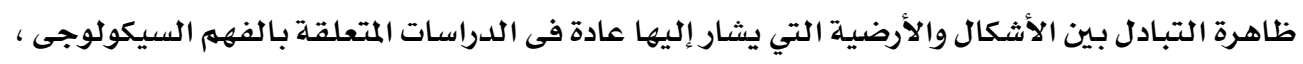

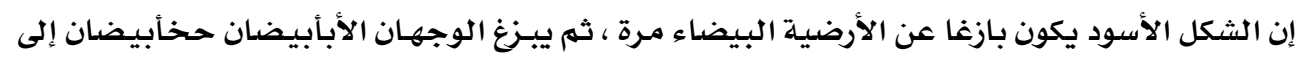

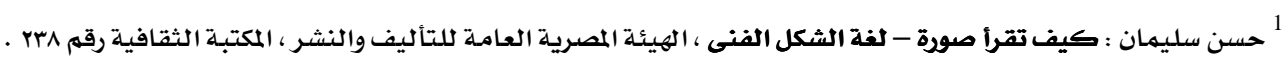


الأمام ليجعل الشكل الأسود خلفية لهما ـ وبالتالي فأننا نكون مجبر يـن على الاعتراف بحقيقة أنه لا

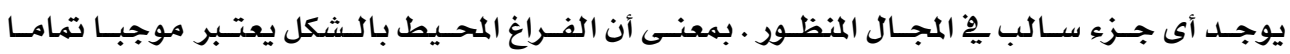

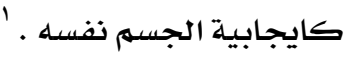
ويأتي دور العقل ِِّ الكشف عن العلاقة الكامنة بين " الشكل والأرضية " - حتى ما يبدو منها

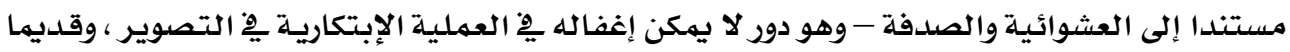

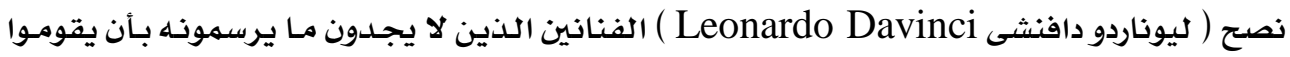

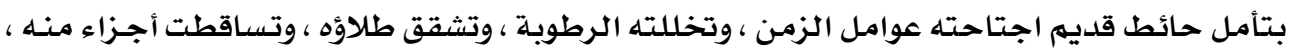

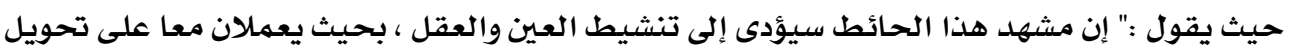

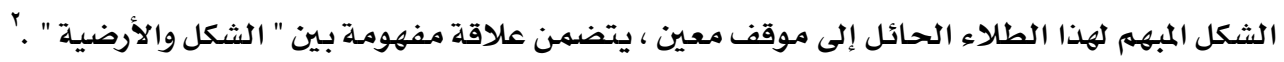
ودور العقل فى تفسير هذه العلاقة من خلال النقاط التالية :

\section{الجوانب الآلية فى تفسير العلاقة بين الشكل والأرضية}

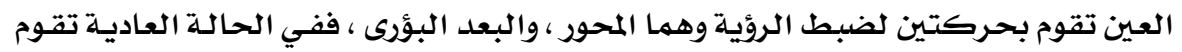

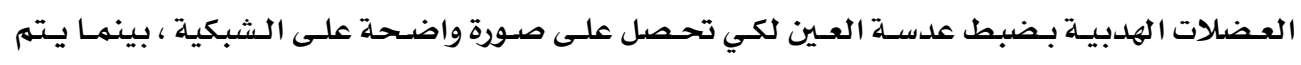

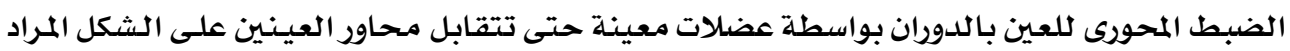

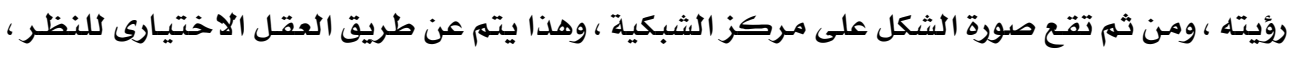

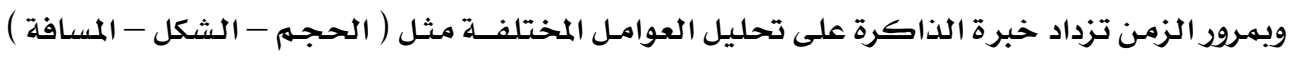

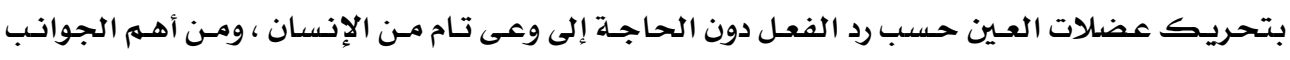

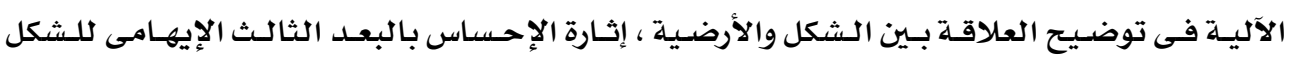

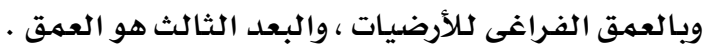

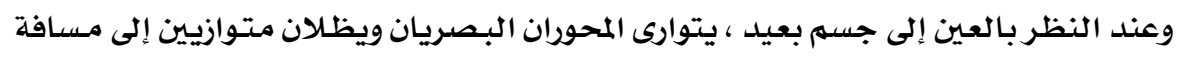

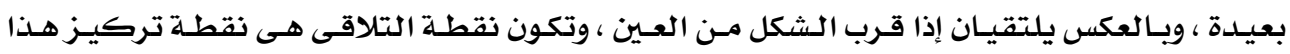

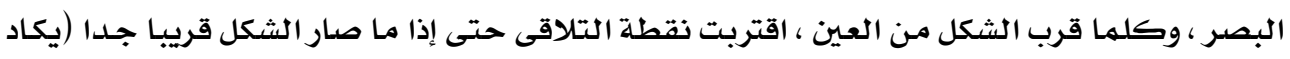

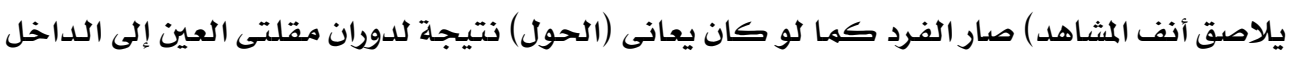

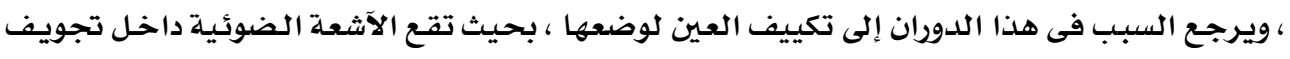

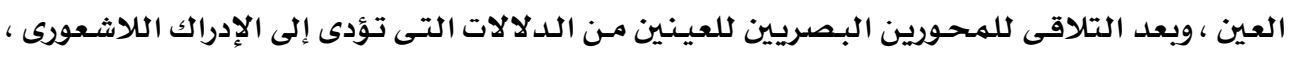

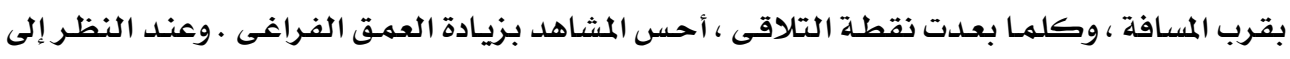

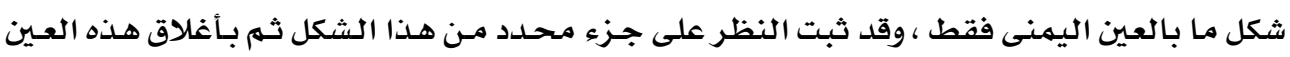

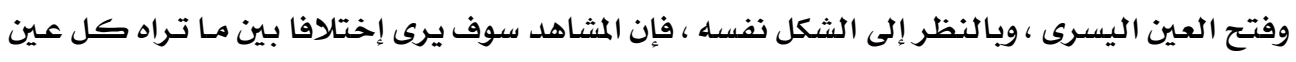

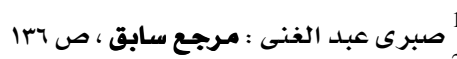

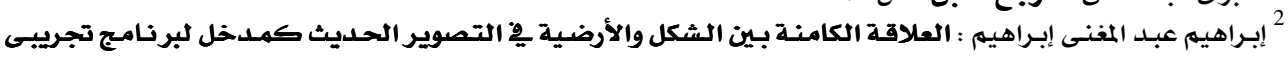

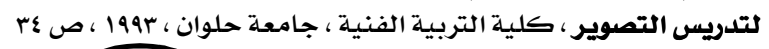


على حدة ، ويتلخص هذا الاختلاف ٍِِ الوضـع النسبى لهذا الجسهم الذي نتظـر إليـه بالنسبة لما يقـع

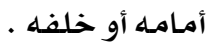

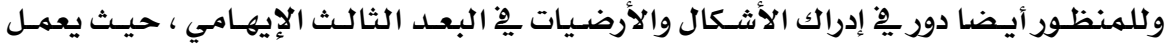

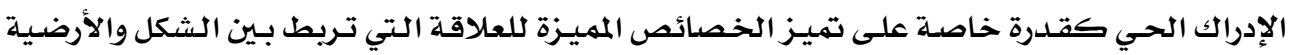
في الفراغ الإدات

\section{التصورات الذاتية فى إدراك العلاقة بين الشكل والأرضية .}

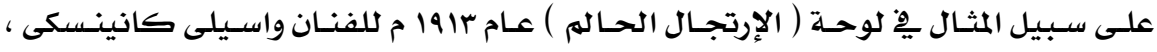

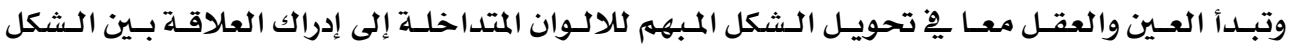

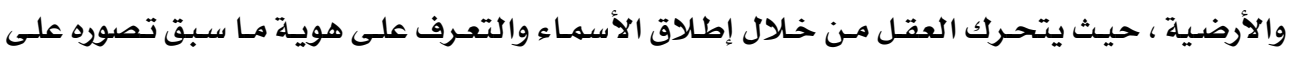

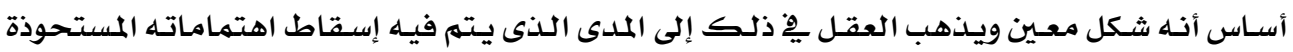

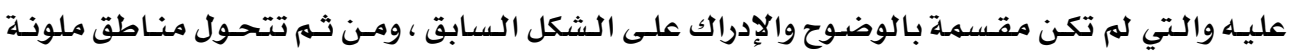

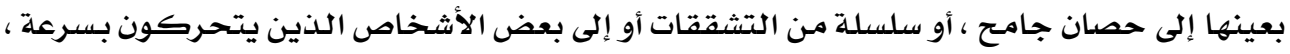

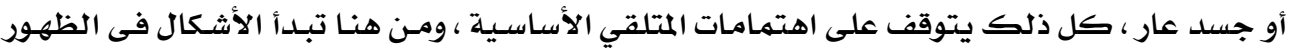

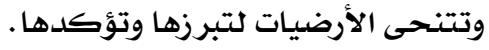

\section{الخبرة السابقة فى تفسير العلاقة بين الشكل والأرضية}

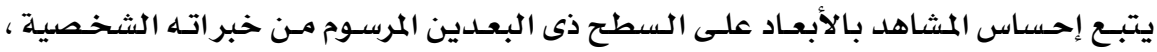

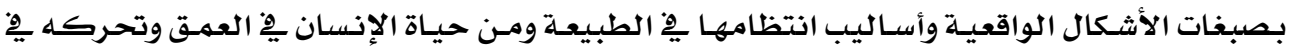

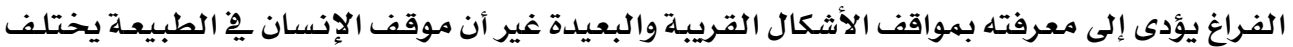

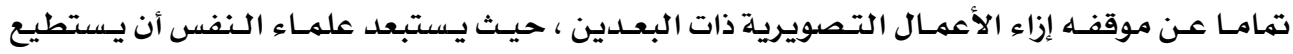

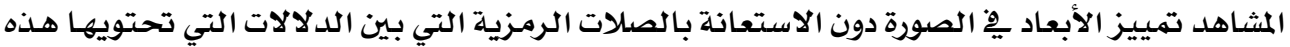

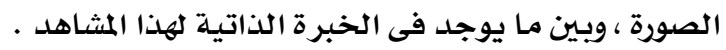

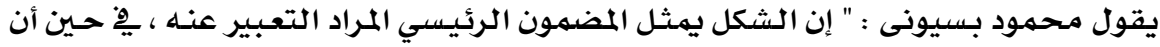

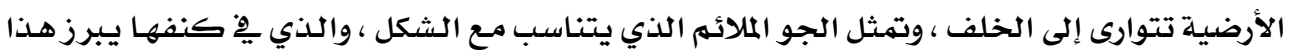

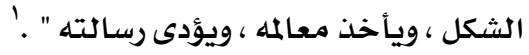

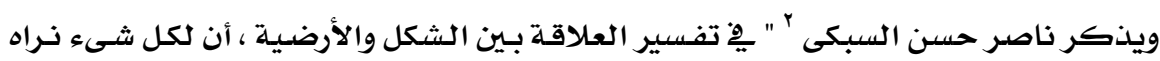

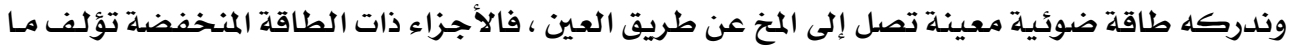

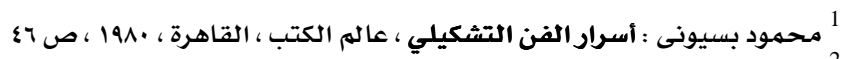

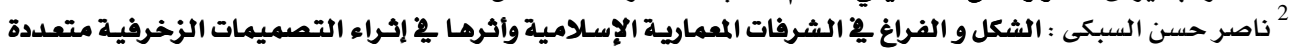

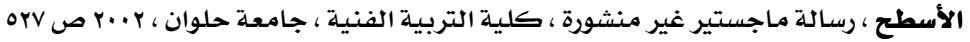

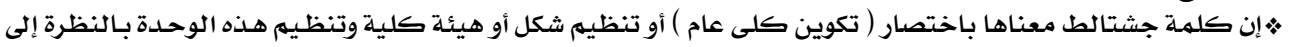

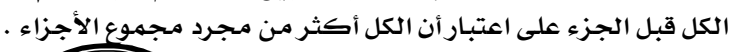


يسميه علماء النفس بالأرضية Ground والأجـزاء ذات الطاقـة المرتفعـة فتضمى مـع بعضها مـا نسميه بالشكل Figure وقد حدد الجشتالطيون *Gestaht حدود الإدراك" على الأسس الآتية :

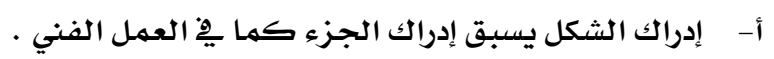

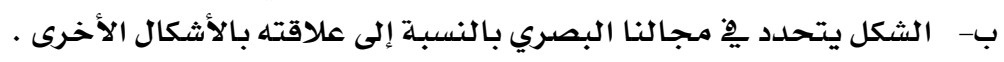

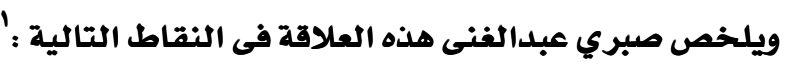

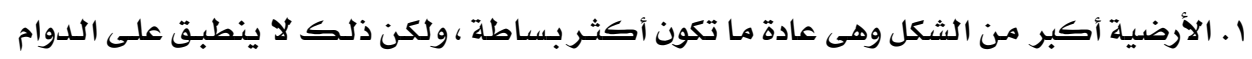

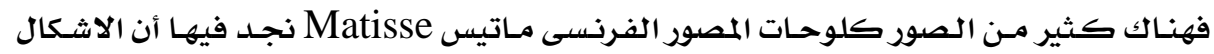

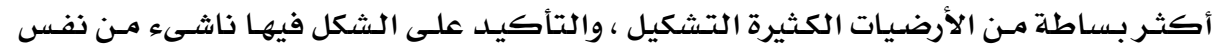

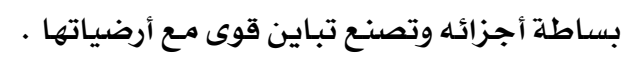

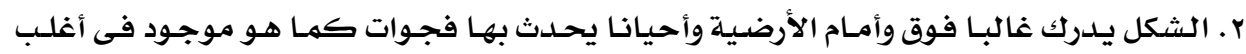

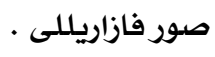

r. الأرضية يهكن إدراكها على أنها مسطح أو أو فضاء .

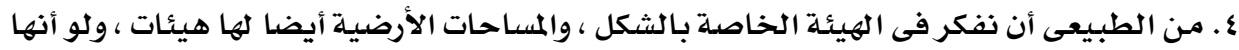

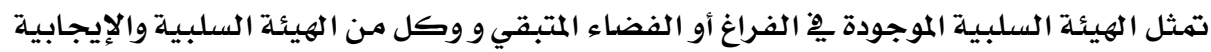

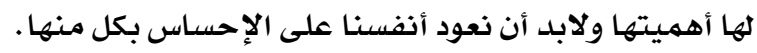

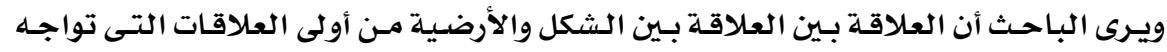

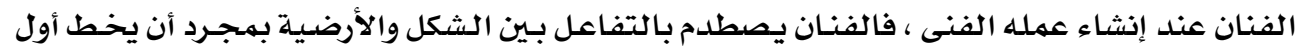

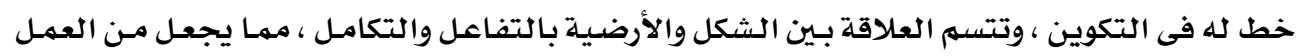

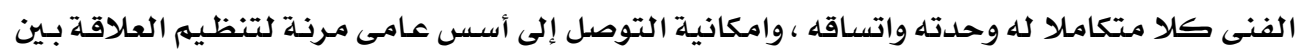

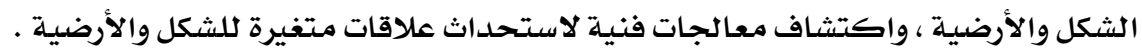

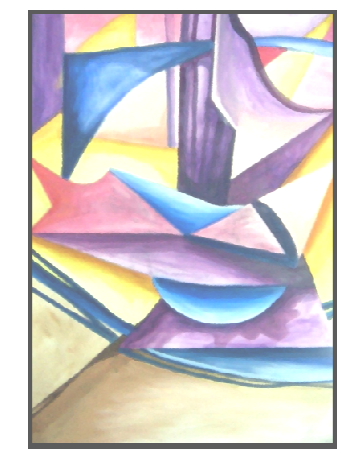

الإطار التطبـيقي :

عمل رقم (1) من أعمال الباحث

صبرى عبد الغنى : مرجع سابق ، ص آIا 


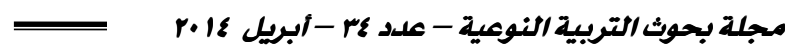
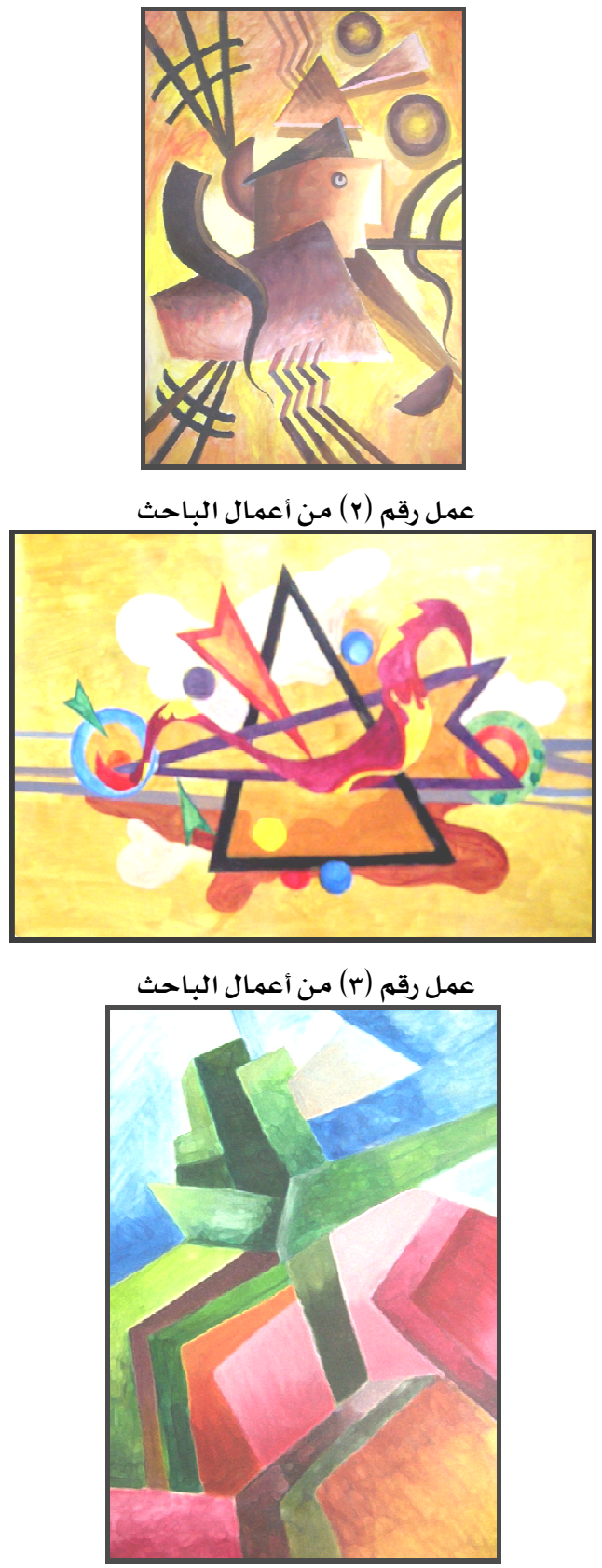

عمل رقم (ع) من أعمال الباحث 


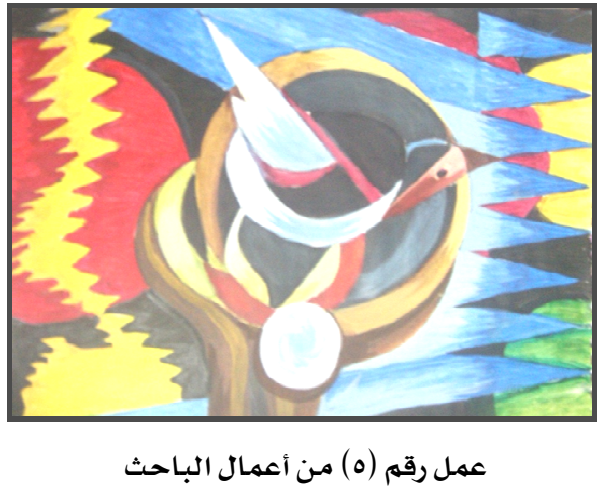

النتائه :

ا ـ الشكل يمثل الصيغة الشاملة لكافة الظواهر المرئية فى الطبيعة والفن

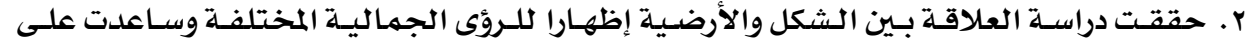
تحقيق أفضل تنظيم شكلى لتحقيق التهاسك ورالتوازن في بناء التهاء الشكل .

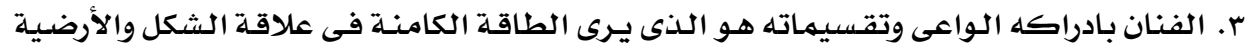

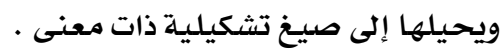
التتوصيات :

يوصى الباحث بأن يكون دور الشكل فى اللوحة وعلاقته بالأرضية مـدخلا مهمـا لبنـاء العهـل

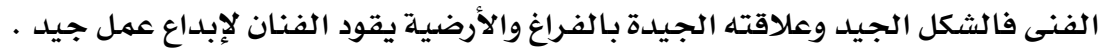
المراجع : المعان أولا : الكتب :

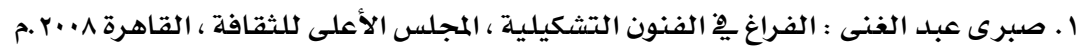

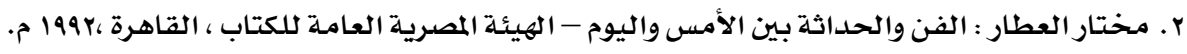

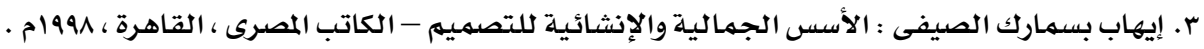

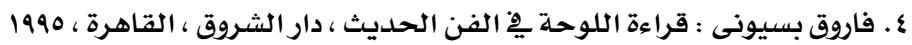

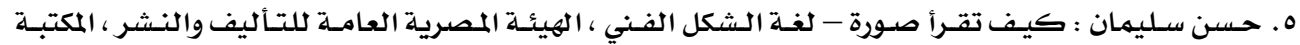

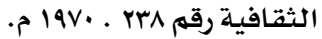

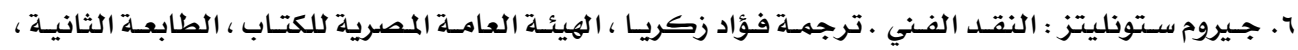

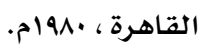

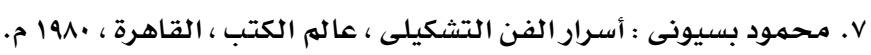
ثانيا : الرسائل العلمية :

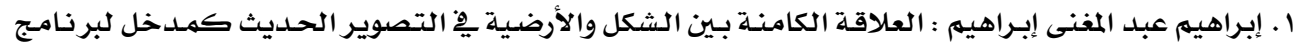

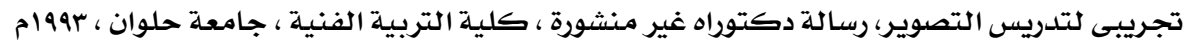




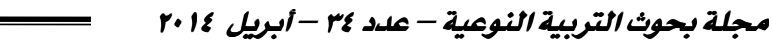

r. محمد ياسين أبو العنين : الدلالات الإدراكية للفراغ ِِّ الأعمال الفنيـة ذات البعدين يِّ مختارات مـن الفن

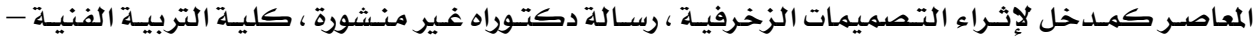

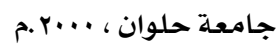

r. مجدى أبو المعاطى البسيونى : مفهوم الشكل والأرضية هِّ الأعمال التصميمية والاستفادة بأعمال (آيشر)

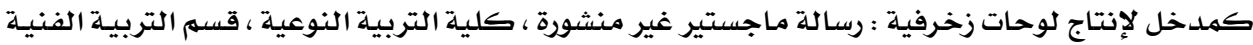

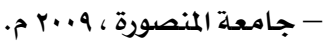

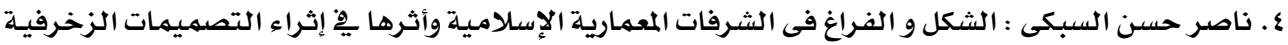

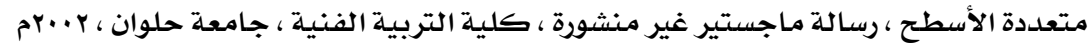
ثالثا : مواقع الإنترنت : ملتعل

1. http://www.basrahcity.net/pather/report/ammh/31.html1 